\title{
Burnout among dutch intensivists
}

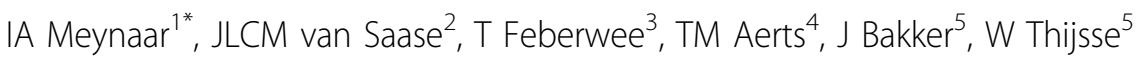 \\ From ESICM LIVES 2015 \\ Berlin, Germany. 3-7 October 2015
}

\section{Introduction}

Burnout in healthcare workers is deleterious both for the patients as well as for the healthcare workers themselves with consequences ranging from less job satisfaction to increased mortality rates. Burnout in intensivists is reportedly high with almost half of French intensivists having burnout symptoms.

\section{Objectives}

The present study was done to estimate incidence and prevalence of burnout in intensivists in the Netherlands and to identify risk factors for burnout.

\section{Methods}

Two online questionnaires were sent: one to all intensivists in the Netherlands and one to the medical directors of Dutch Intensive Care Units (ICUs).

\section{Results}

A reply was received of 318 out of 664 intensivists (47.9\%). Results of 272 intensivists were evaluable, 12 of whom $(4.4 \%)$ were diagnosed with burnout at the time of the questionnaire. No association was found between working conditions or personal characteristics and burnout, except for the association between burnout and conflict with the hospital management and between burnout and having complaints filed against one. From the medical directors questionnaire it was found that 7.4\% of intensivists suffered from burnout in 2013 .

\section{Conclusions}

Incidence and prevalence of burnout among Dutch intensivist was found to be unexpectedly low as compared to the literature. No firm associations were found between burnout and working conditions or personal characteristics. The low incidence and prevalence of burnout in Dutch intensivists might be explained be a

${ }^{1}$ HagaZiekenhuis, ICU, Delft, Netherlands

Full list of author information is available at the end of the article lower workload for intensivists as compared to the literature.

\section{Acknowledgement}

This study was done with support of the Dutch Society for Intensive Care

\section{Authors' details}

${ }^{1}$ HagaZiekenhuis, ICU, Delft, Netherlands. ${ }^{2}$ ErasmusMC University Medical Center, Department of Internal Medicine, Rotterdam, Netherlands. ${ }^{3}$ Reinier de Graaf Hospital, Hospital Pharmacy, Delft, Netherlands. ${ }^{4}$ RET, Department of Health Management, Rotterdam, Netherlands. ${ }^{5}$ ErasmusMC University Medical Center, Department of Intensive Care Adults, Rotterdam, Netherlands.

Published: 1 October 2015

doi:10.1186/2197-425X-3-S1-A140

Cite this article as: Meynaar et al:: Burnout among dutch intensivists. Intensive Care Medicine Experimental 2015 3(Suppl 1):A140.

Submit your manuscript to a SpringerOpen ${ }^{\odot}$ journal and benefit from:

- Convenient online submission

- Rigorous peer review

- Immediate publication on acceptance

- Open access: articles freely available online

- High visibility within the field

- Retaining the copyright to your article

Submit your next manuscript at $>$ springeropen.com (c) 2015 Meynaar et al.; This is an Open Access article distributed under the terms of the Creative Commons Attribution License (http:// creativecommons.org/licenses/by/4.0), which permits unrestricted use, distribution, and reproduction in any medium, provided the original work is properly cited. 